\title{
EVALUASI KONSEP GREEN OPEN SPACE TERHADAP KUALITAS TAMAN PADA PROGRAM PENGEMBANGAN KOTA HIJAU (P2KH) KECAMATAN KENDAL (Studi Kasus: Taman Stadion Utama, Langenharjo, Gajah Mada)
}

\author{
Majdina Astri Graharistiara ${ }^{1)}$; Hasti Widyasamratri ${ }^{2)}$ \\ Program Studi Perencanaan Wilayah dan Kota Universitas Islam Sultan Agung Semarang ${ }^{1,2)}$
}

ABSTRACT

Green Open Space is an urban expanse covered by some of the trees as a shade area of the city and as the fulfillment of the needs public spaces for the community in activities and social. Efforts continue to be undertaken by the Green Open Space embodiment of Government, one that is by pioneering the implementation of 'Program Pengembangan Kota Hijau'(P2KH) in improving the quantity and quality of Green Open Space in the area of the county or city. One form of Green Open Space i.e. the garden city that serves to improve the quality of urban and support the needs of the community in getting space to relax and leisure. The condition of children in district Kendal based on information from the community a lot of damage to either the environment or the facilities therein. This study aims to evaluate the application of Green Open Space on quality Grounds in the 'Program Pengembangan Kota Hijau'(P2KH) sub district of Kendal which consists of the Stadion Utama, Langenharjo and Gajah Mada Parks. The method used was qualitative with deductive approach to rationalistic Unitarians. The analysis used a descriptive analysis i.e. qualitative and verification. Results from the study found that: 1) implementation evaluation results of Green Open Space in the gardens of the town Kendal not optimal, particularly on the Stadion Utama and Langenharjo Parks is still passive because it has not been supported with supporting facilities ; 2) evaluation results applying the Green Community is not optimal because there hasn't been an active ongoing activities so that it can not realize the active role of the community as a community in realizing the green city in district of Kendal; 3) factors that influence the application of optimal yet Green Open Space that is the location of the parks are not on the main road, the spread of vegetation are not optimal in improving microclimate because the settings are less noticed aspects of the function and benefits, passive Parks conditions due to lack of support facilities and the lack of appeal on the parks because the Setup and the pattern of plants that don't meet aesthetic; 4) factors that influence has not been optimal application of the Green Community that is constrained funds and lack of public awareness in maintaining and safeguarding the environment.

Key Words: Green Open Space, City Park, Green City

\section{ABSTRAK}

Ruang Terbuka Hijau (RTH) perkotaan merupakan suatu hamparan yang ditumbuhi oleh beberapa pepohonan sebagai area peneduh kota dan sebagai pemenuhan kebutuhan ruang publik bagi masyarakat dalam beraktivitas dan bersosial. Upaya perwujudan RTH terus dilakukan oleh pemerintah, salah satunya yaitu dengan merintis pelaksanaan Program Pengembangan Kota Hijau (P2KH) dalam meningkatkan kuantitas dan kualitas RTH di wilayah Kabupaten maupun Kota. Salah satu bentuk RTH yaitu taman kota yang berfungsi untuk memperbaiki kualitas perkotaan dan menunjang kebutuhan masyarakat dalam mendapatkan ruang bersantai dan berekreasi. Kondisi taman di Kecamatan Kendal berdasarkan keterangan dari masyarakat banyak mengalami kerusakan baik lingkungan maupun fasilitas didalamnya. Penelitian ini bertujuan untuk mengevaluasi penerapan Green Open Space terhadap Kualitas Taman dalam Program Pengembangan Kota Hijau (P2KH) Kecamatan Kendal yang terdiri dari Taman Stadion Utama, Taman Langenharjo dan Taman Gajah Mada. Metode yang digunakan adalah deduktif kualitatif dengan pendekatan rasionalistik. Analisis yang digunakan yaitu analisis deskriptif kualitatif dan verifikasi. Hasil dari penelitian ditemukan bahwa: 1) Hasil evaluasi penerapan Green Open Space pada taman-taman kota Kecamatan Kendal belum optimal, terutama pada Taman Stadion Utama dan Taman Langenharjo yang masih pasif karena belum ditunjang dengan fasilitas pendukung; 2) Hasil evaluasi penerapan Green Community belum optimal karena belum ada kegiatan aktif yang berkelanjutan sehingga belum dapat mewujudkan peran aktif masyarakat sebagai komunitas dalam mewujudkan Kota Hijau di Kecamatan Kendal; 3) Faktor-faktor yang mempengaruhi belum optimalnya penerapan Green Open Space yaitu lokasi taman tidak berada di jalan utama, persebaran vegetasi yang belum optimal dalam memperbaiki iklim mikro karena penataannya kurang memperhatikan aspek fungsi dan manfaat, kondisi taman yang pasif karena kurangnya fasilitas pendukung serta tidak adanya daya tarik pada taman karena penataan dan pola tanaman yang tidak memenuhi estetika; 
Jurnal Planologi

Vol. 14, No. 2, Oktober 2017

4) Faktor yang mempengaruhi belum optimalnya penerapan Green Community yaitu terkendala dana serta kurangnya kesadaran masyarakat dalam memelihara dan menjaga lingkungan.

Kata Kunci: Ruang Terbuka Hijau, Taman Kota, Kota Hijau 


\section{PENDAHULUAN}

Ruang Terbuka Hijau (RTH) merupakan suatu hamparan luas yang memanjang berbentuk jalur atupun mengelompok yang penggunaannya bersifat terbuka serta sebagai media tumbuh berbagai tanaman dan pepohonan. RTH menurut Hakim (2008) tidak hanya sebagai area pengisian tumbuh-tumbuhan, namun juga sebagai bentuk pemanfaatan ruang terbuka bagi masyarakat. Bentuk dari RTH salah satunya yaitu berupa Taman. Taman menurut Nazaruddin (1998) merupakan area RTH yang biasanya berada pada lokasi strategis dan dimanfaatkan oleh masyarakat untuk berbagai keperluan/aktivitas.

Perwujudan RTH 30\% pada wilayah Kabupaten maupun Kota atau lebih dikenal sebagai perwujudan Kota Hijau diupayakan dengan merintis pelaksanaan Program Pengembangan Kota Hijau (P2KH) dengan didasarkan pada pengembangan 8 atribut Kota Hijau yang terdiri dari Green Planning and Design, Green Open Space, Green Transportation, Green Building, Green Community, Green Energy, Green Waste, dan Green Water. Kabupaten Kendal sendiri merupakan salah satu dari 15 wilayah kabupaten/kota di Jawa Tengah yang terpilih untuk mengembangkan kota hijau. Fokus Kabupaten Kendal pada Tahap I menurut Ir. M Nuur Fauzi, MT selaku Kepala Dinas Ciptaru (sekarang berganti nama menjadi Dinas Pekerjaan Umum dan Penataan Ruang) yaitu meningkatkan RTH pada Kecamatan Kendal yang merupakan kawasan pusat dari Kabupaten Kendal (EDY/Humas, 2013). Kegiatan yang dilakukan terkait dengan peningkatan Green Open Space dan Green Community dengan meningkatkan kualitas dan kuantitas RTH serta pelibatan komunitas hijau dalam setiap kegiatan P2KH.

Kondisi Taman di Kabupaten Kendal berdasarkan laporan masyarakat mengalami kerusakan, baik pada lingkungan taman maupun fasilitas di dalamnya. Beberapa jenis kerusakan tersebut yaitu banyaknya rumput yang mati, sampah yang tersebar sembarangan serta aksi vandalisme (MJ, 2016). Oleh karena itu, tujuan dari penelitian ini adalah untuk mengevaluasi penerapan Green Open Space dan Green Community terhadap kualitas taman dalam Program Pengembangan Kota Hijau (P2KH) Kecamatan Kendal. Adapun sasaran yang akan dilakukan yaitu:

1. Mengevaluasi Penerapan Green Open Space dan Green Community terhadap kualitas taman dalam Program Pengembangan Kota Hijau (P2KH) Kecamatan Kendal; 
2. Menemukan faktor-faktor yang mempengaruhi penerapan Green Open Space dan Green Community terhadap kualitas taman dalam Program Pengembangan Kota Hijau (P2KH) Kecamatan Kendal.

Ruang Lingkup Kawasan dalam penelitian ini yaitu taman-taman yang terbentuk setelah adanya Program Pengembangan Kota Hijau (P2KH) Kecamatan Kendal yang terdiri dari Taman Stadion Utama di Kelurahan Kebondalem, Taman Langenharjo di Kelurahan Langenharjo serta Taman Gajah Mada di Kelurahan Karangsari.

\section{METODOLOGI PENELITIAN}

Metode yang digunakan dalam studi ini yaitu metode deduktif dengan analisis deskriptif kualitatif untuk menjabarkan hasil observasi dengan paradigma rasionalistik. Metode deduktif merupakan suatu metode yang menguraikan sesuatu yang umum menjadi khusus. Penelitian dengan metode deduktif menggunakan acuan dari sebuah teori lalu di verifikasi antara teori dengan realita di lapangan guna membuktikan kebenaran dari teori tersebut.

Tahap pengumpulan data yang dilakukan dalam penelitian ini adalah dengan mengumpulkan data primer dan sekunder. Pengumpulan data primer dilakukan dengan cara:

1. Observasi

Observasi yang dilakukan bertujuan untuk mengkaji bagaimana kondisi eksisting pada ketiga Taman di dalam P2KH Kecamatan Kendal yaitu Taman Stadion Utama, Taman Langenharjo dan Taman Gajah Mada.

2. Wawancara

Wawancara ditujukan kepada pihak ahli, yaitu pada pegawai Bidang Tata Ruang Dinas Pekerjaan Umum dan Penataan Ruang Kabupaten Kendal serta Forum Komunitas Hijau di Kabupaten Kendal. Wawancara juga dilakukan terhadap pengunjung taman dengan menggunakan teknik snowball sampling yaitu teknik penentuan sampel yang mula-mula jumlahnya kecil, kemudian membesar sesuai dengan kebutuhan dari jawaban yang ingin didapatkan.

Sedangkan untuk pengumpulan data sekunder dilakukan dengan melakukan survey instansi untuk mendapatkan data dan dokumen terkait dengan Program Pengembangan Kota Hijau (P2KH) kabupaten Kendal serta mengkaji literatur dari internet maupun buku. 
Evaluasi menurut William N. Dunn (2000) selain menghasilkan kesimpulan mengenai seberapa jauh masalah terselesaikan, juga menyumbang klarifikasi dan kritik terhadap nilai-nilai yang mendasari kebijakan, serta membantu dalam penyesuaian dan perumusan kembali masalah.

Ruang Terbuka Hijau (RTH) Kota menurut Fandeli (2004) terdiri dari pertamanan kota, kawasan hijau hutan kota, kawasan hijau rekreasi kota, kawasan hijau kegiatan olahraga, dan kawasan hijau pekarangan.

\section{Taman Kota}

Fungsi taman kota menurut Stephen Carr (1992) yaitu untuk memenuhi kebutuhan rekreasi yang berdasarkan pada pertemuan masyarakat serta perlindungan landscape yang unik. Taman kota biasanya berlokasi dekat dengan pusat kota dan dapat pula berupa taman hijau dengan rerumputan dan aneka macam pepohonan yang berlokasi di kawasan pusat kota.

\section{Kota Hijau}

Penghijauan kota menurut Zoer'aini (2003) adalah suatu usaha untuk menghijaukan kota dengan melaksanakan pengelolaan taman-taman kota, taman-taman lingkungan, jalur hijau, hutan kota dan sebagainya. Salah satu upaya penghijauan kota yaitu dengan adanya Program Pengembangan Kota Hijau (P2KH) dalam rangka memenuhi target RTH sebesar 30\% di wilayah Kabupaten maupun Kota. Pelaksanaan P2KH sendiri didasarkan pada pengembangan 8 atribut Kota Hijau yang terdiri dari Green Planning and Design, Green Open Space, Green Transportation, Green Building, Green Community, Green Energy, Green Waste, dan Green Water.

\section{Green Open Space}

Upaya meningkatkan mutu kualitas maupun kuantitas ruang terbuka hijau (RTH) perkotaan sesuai dengan karakter Kota atau Kabupaten dengan proporsi minimal RTH kota adalah 30\% dari luas kawasan. Atribut ini merupakan salah satu atribut utama yang termasuk dalam langkah awal pengembangan kota hijau.

\section{Green Community}

Melibatkan peran aktif masyarakat atau komunitas serta institusi swasta dalam pengembangan kota hijau. Cakupan Green Community dalam pengembangan kota hijau yaitu peran masyarakat sebagai pelaku dan peran pemerintah sebagai fasilitator. 


\section{HASIL DAN PEMBAHASAN}

Hasil penelitian diperoleh melalui observasi pengamatan secara langsung pada lokasi penelitian dengan didukung wawancara terhadap pihak Dinas terkait dan pengunjung maupun masyarakat yang bertempat tinggal di sekitar lokasi taman. Unit amatan terbagi ke dalam 2 parameter, yaitu Green Open Space yang terdiri dari 3 lokasi taman yang kemudian dibagi lagi ke dalam sub unit yang telah disesuaikan dengan variabel yang digunakan dan Green Community yang meliputi peran pemerintah, masyarakat dan forum komunitas yang tergabung ke dalam Program Kota Hijau Kabupaten Kendal.

Tahapan dalam mengevaluasi penerapan green open space terhadap kualitas taman dalam Program Pengembangan Kota Hijau (P2KH) dibahas melalui pengkajian 6 variabel, yaitu lokasi taman, luas dan skala pelayanan taman, kesesuaian vegetasi taman, fasilitas penunjang taman, pemanfaatan area taman, serta daya tarik taman. Unit amatan terdiri dari 3 taman yaitu Taman Stadion Utama, Taman Langenharjo, dan Taman Gajah Mada. Ketiga lokasi taman tersebut merupakan taman kota P2KH tahap 1 di Kecamatan Kendal yang merupakan pusat wilayah dari Kabupaten Kendal.

\section{1) Kondisi Eksisting Penerapan Green Open Space A. Green Open Space Taman Stadion Utama}

Tabel 1 Penerapan Green Open Space Taman Stadion Utama

\begin{tabular}{|c|c|c|}
\hline No. & Variabel & Kondisi di Lapangan \\
\hline 1. & Lokasi & $\begin{array}{l}\text { a. Tidak terletak di jalan utama. } \\
\text { b. Berjarak } 1,8 \mathrm{~km} \text { dari pusat Kecamatan Kendal. } \\
\text { c. Mudah dijangkau oleh penduduk sekitar lokasi stadion utama. } \\
\text { d. Tidak dilalui oleh sarana transportasi umum seperti bus maupun } \\
\text { mikrobus. }\end{array}$ \\
\hline 2. & $\begin{array}{l}\text { Luas dan Skala } \\
\text { Pelayanan }\end{array}$ & $\begin{array}{l}\text { a. Secara teori, Taman Stadion Utama belum dapat dikategorikan sebagai } \\
\text { taman kota karena luasannya kurang dari } 144.000 \mathrm{~m}^{2} \text {. } \\
\text { e. Luas Taman Stadion Utama yaitu } 5.000 \mathrm{~m}^{2} \text { sehingga telah sesuai } \\
\text { dengan pedoman Masterplan P2KH dalam menyumbangkan kebutuhan } \\
\text { RTH perkotaan. }\end{array}$ \\
\hline 3. & $\begin{array}{l}\text { Kesesuaian } \\
\text { Vegetasi }\end{array}$ & $\begin{array}{l}\text { a. Keberadaan softscape di Taman Stadion Utama telah menyumbang } 70 \% \\
\text { dari luasan taman. } \\
\text { b. Terdiri dari berbagai macam pohon peneduh serta tanaman hias baik } \\
\text { pohon, semak maupun perdu. } \\
\text { c. Tinggi tanaman peneduh rata-rata telah mencapai } 5 \mathrm{~m} \text { dengan kondisi } \\
\text { batang yang besar dan tinggi. } \\
\text { d. Tanaman peneduh telah menaungi area pedestrian dan bangku taman. } \\
\text { e. Terdapat jenis tanaman peneduh yang daunnya mudah gugur sehingga } \\
\text { mengotori area pedestrian. } \\
\text { f. Keberadaan vegetasi pada Taman Stadion Utama dapat mengurangi } \\
\text { tingkat polusi karena terdapat tanaman pandan bali yang persebarannya }\end{array}$ \\
\hline
\end{tabular}




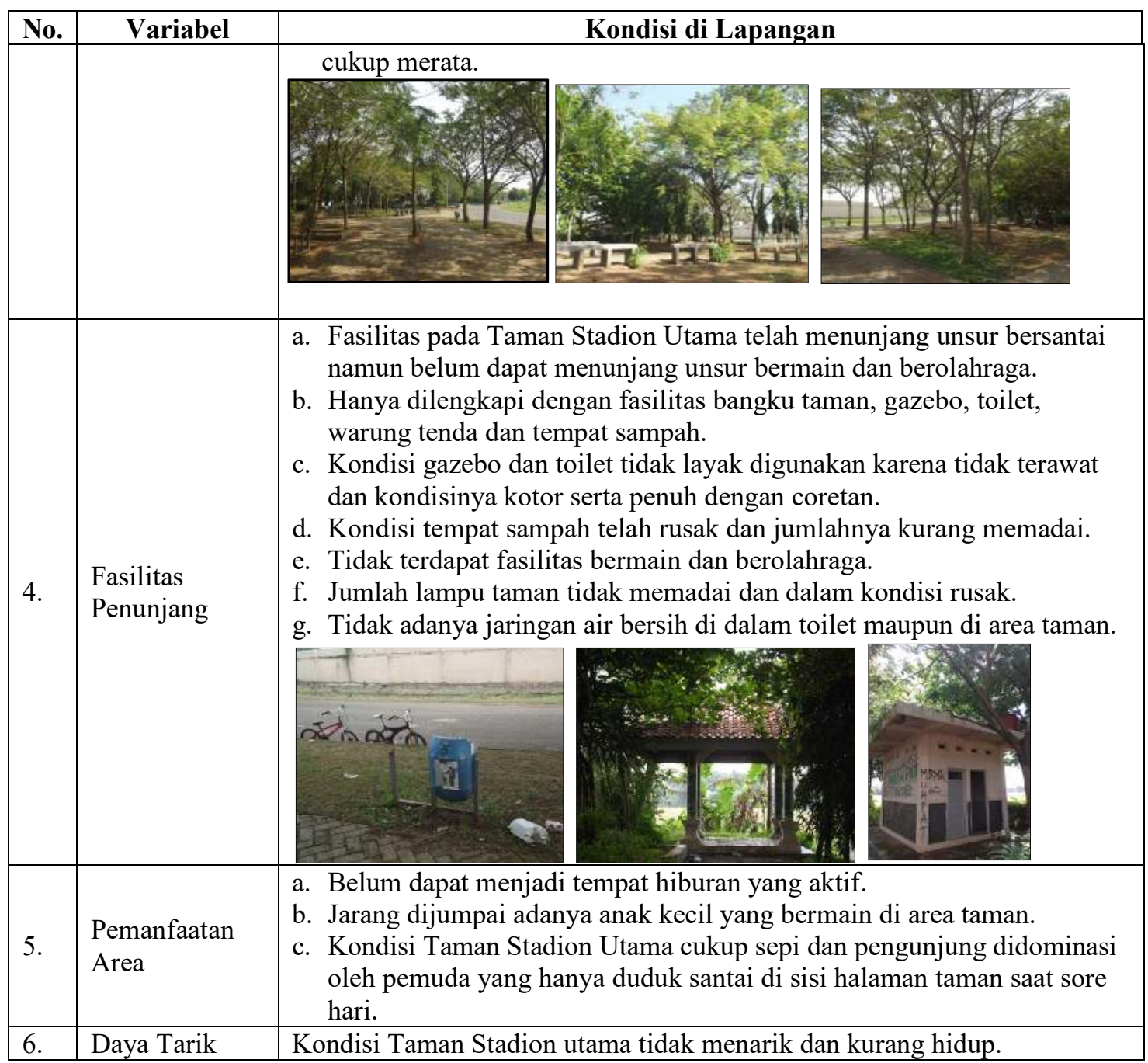

Sumber: Analisa Penyusun, 2017

\section{B. Green Open Space Taman Langenharjo}

\section{Tabel 2 Penerapan Green Open Space Taman Langenharjo}

\begin{tabular}{|l|l|l|}
\hline No. & Variabel & \multicolumn{1}{c|}{ Kondisi di Lapangan } \\
\hline & & $\begin{array}{l}\text { a. Tidak terletak di jalan utama. } \\
\text { b. Berjarak 1,6 km dari pusat Kecamatan Kendal. } \\
\text { c. Hanya mudah dijangkau oleh warga yang bertempat tinggal di } \\
\text { lingkungan perumahan dekat area taman. } \\
\text { d. Tidak dilalui oleh sarana transportasi umum seperti bus maupun } \\
\text { mikrobus. }\end{array}$ \\
\hline 2. & Lokasi & $\begin{array}{l}\text { a. Secara teori, Taman Langenharjo belum dapat dikategorikan sebagai } \\
\text { taman kota karena luasannya kurang dari } 144.000 \mathrm{~m}^{2} .\end{array}$ \\
Pelayanan & $\begin{array}{l}\text { b. Luas Taman Langenharjo yaitu } 6.000 \mathrm{~m}^{2} \text { sehingga telah sesuai dengan } \\
\text { pedoman Masterplan P2KH dalam menyumbangkan kebutuhan RTH } \\
\text { perkotan. }\end{array}$ \\
\hline
\end{tabular}




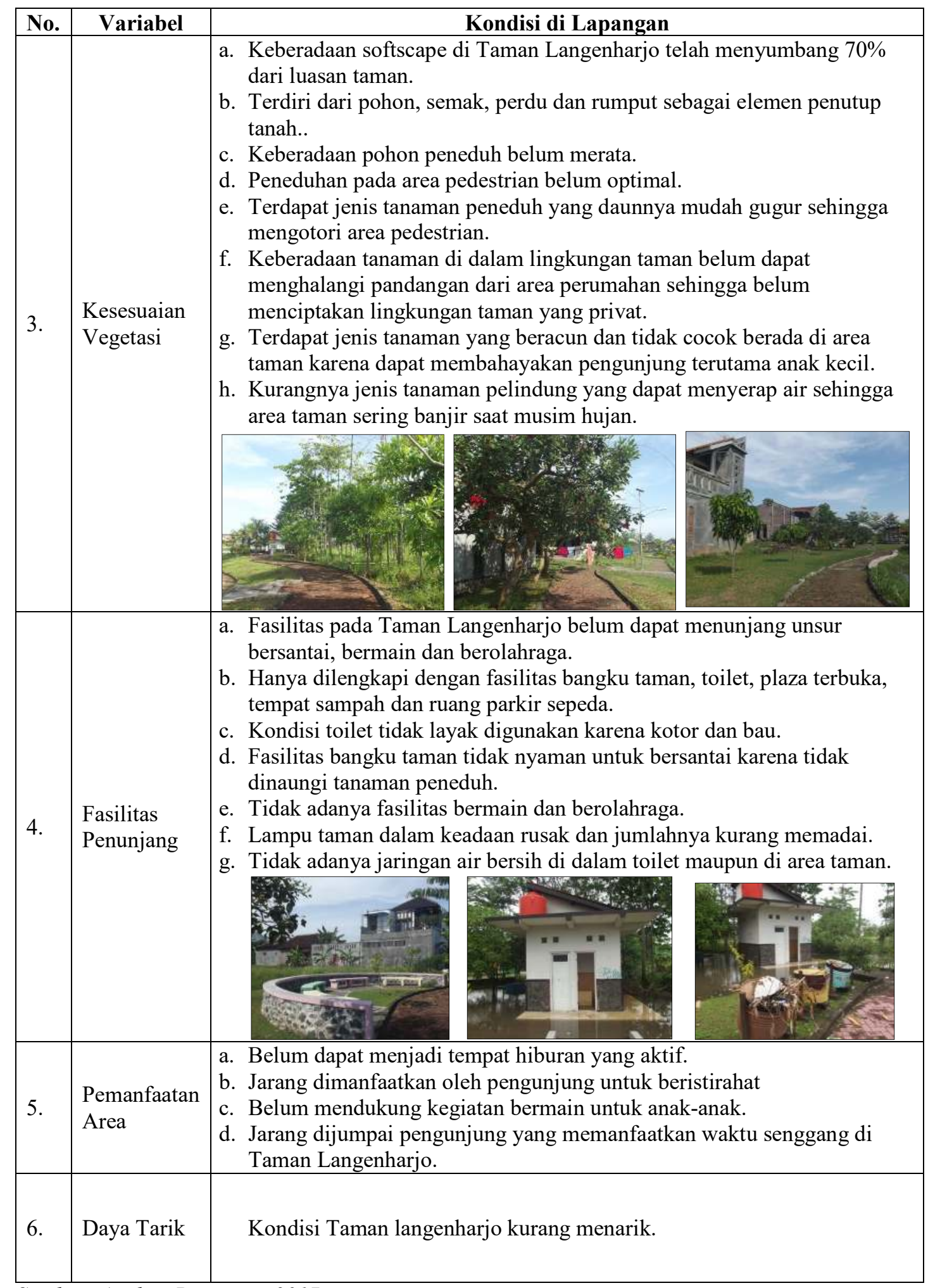

Sumber: Analisa Penyusun, 2017

\section{Green Open Space Taman Gajah Mada \\ Tabel 3 Penerapan Green Open Space Taman Gajah Mada}




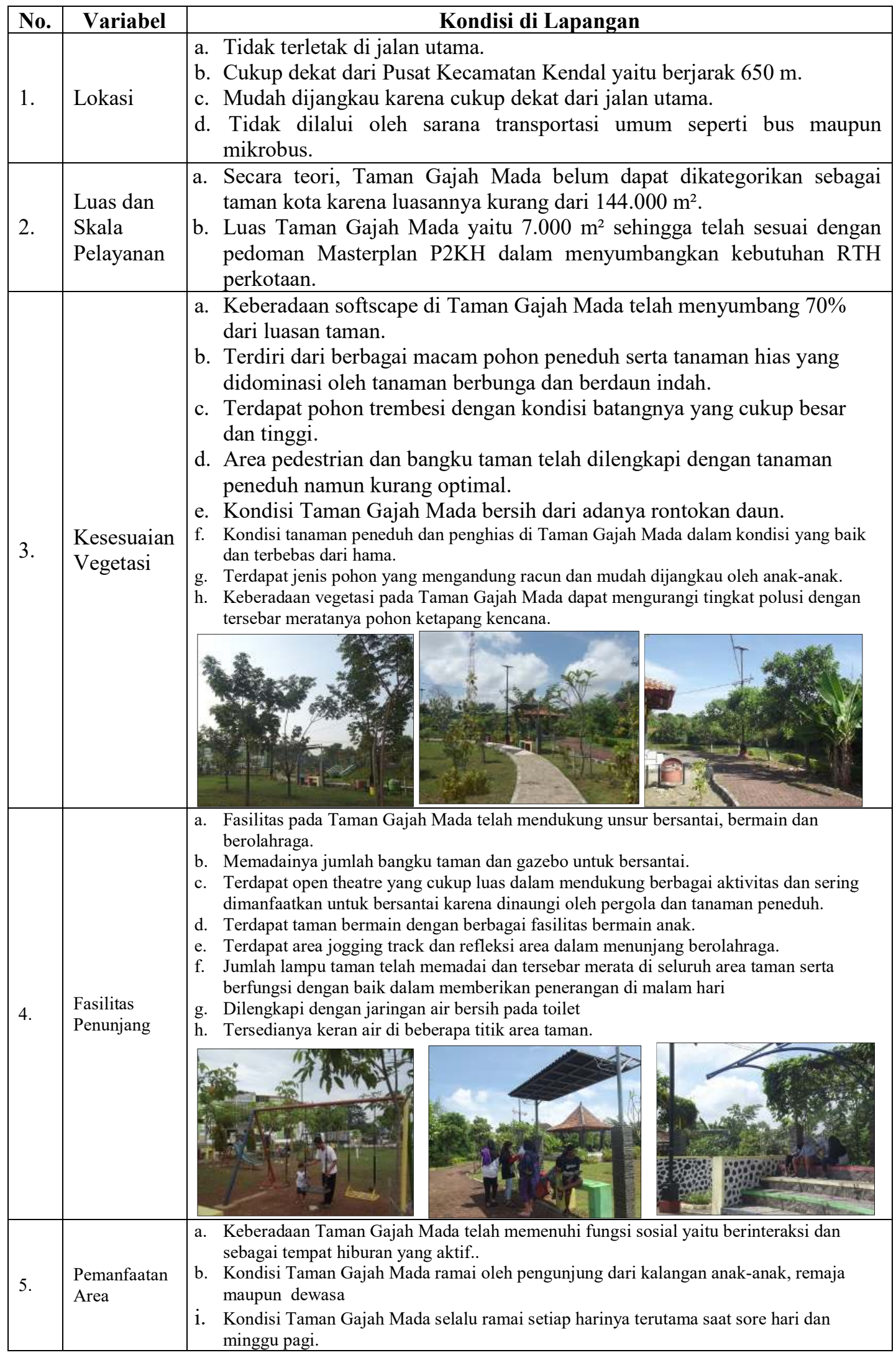




\begin{tabular}{|l|l|ll|}
\hline No. & Variabel & \multicolumn{1}{c|}{ Kondisi di Lapangan } \\
\hline 6. & Daya Tarik & $\begin{array}{l}\text { a. } \\
\text { Terdiri dari beragam jenis tanaman hias baik dengan tekstur dan warna yang unik serta } \\
\text { menarik. }\end{array}$ \\
j. $\begin{array}{l}\text { Desain taman yang cukup menarik dan terdapat signage serta desain pintu masuk taman } \\
\text { yang menarik pengunjung karena sering dijadikan sebagai spot berfoto. }\end{array}$ \\
\hline
\end{tabular}

\section{Green Community P2KH Kecamatan Kendal}

Tabel 4 Penerapan Green Community

\begin{tabular}{|c|c|c|}
\hline No. & Variabel & Kondisi di Lapangan \\
\hline 1. & $\begin{array}{l}\text { Peran } \\
\text { Pemerintah }\end{array}$ & $\begin{array}{l}\text { a. Pemerintah yaitu Dinas Pekerjaan Umum dan Penataan Ruang (DPUPR) } \\
\text { Kabupaten Kendal telah melaksanakan penghijauan kota dan } \\
\text { membangun taman beserta kelengkapannya. } \\
\text { b. Upaya pemeliharaan taman-taman masih belum optimal. } \\
\text { c. Kegiatan bimbingan dan penyuluhan akan bidang pertamanan kurang } \\
\text { optimal. Pemerintah telah berupaya dalam mengawasi dan } \\
\text { mengendalikan keindahan kota. }\end{array}$ \\
\hline 2. & $\begin{array}{l}\text { Partisipasi } \\
\text { Masyarakat }\end{array}$ & $\begin{array}{l}\text { a. Beberapa kalangan masyarakat yang tergabung dalam FKH terlibat } \\
\text { langsung dalam setiap kegiatan } \mathrm{P} 2 \mathrm{KH} \text {. } \\
\text { d. Aksi nyata dalam upaya perwujudan } \mathrm{P} 2 \mathrm{KH} \text { belum berjalan secara } \\
\text { berkelanjutan dan sejak tahun } 2015 \text { hingga } 2017 \text { belum ada kegiatan } \\
\text { aktif dalam rangka perwujudan Kota Hijau. }\end{array}$ \\
\hline 3. & $\begin{array}{l}\text { Sikap } \\
\text { Masyarakat } \\
\text { akan } \\
\text { Kepedulian } \\
\text { Lingkungan }\end{array}$ & $\begin{array}{l}\text { Beberapa kalangan masyarakat belum memiliki kesadaran dalam menjaga } \\
\text { lingkungan, ditandai dengan kondisi taman yang buruk karena masih } \\
\text { banyak ditemui sampah-sampah berserakan dan banyaknya aksi vandalisme } \\
\text { pada beberapa fasilitas taman. }\end{array}$ \\
\hline
\end{tabular}

Sumber: Analisa Penyusun, 2017

\section{2) Hasil Evaluasi Penerapan Green Open Space dan Green Community}

\section{A. Hasil Evaluasi Penerapan Green Open Space}

Hasil evaluasi penerapan Green Open Space terhadap kualitas taman pada ke-tiga taman

P2KH sesuai dengan sasaran dari pedoman Masterplan P2KH adalah sebagai berikut:

1) Taman Stadion utama hanya mencapai $53 \%$, dengan pencapaian belum maksimal yaitu pada akses lokasi serta fasilitas penunjang yang belum memadai dan kondisinya yang tidak terawat.

2) Taman Langenharjo hanya mencapai $23 \%$, dengan pencapaian belum maksimal yaitu hampir pada seluruh variabel terutama pada kesesuaian vegetasinya yang belum optimal dalam memberikan keteduhan dan tidak memadai serta tidak terawatnya fasilitas penunjang.

3) Taman Gajah Mada telah mencapai $80 \%$, dengan kondisi taman yang telah cukup aktif karena banyak dikunjungi oleh masyarakat serta memadainya berbagai fasilitas penunjang, pencapaian belum maksimal yaitu pada kondisi taman yang kurang teduh 
saat siang hari karena kondisi vegetasinya yang masih muda sehingga belum optimal dalam memberikan keteduhan.

\section{B. Hasil Evaluasi Penerapan Green Community:}

Hasil evaluasi menunjukkan bahwa penerapan Green Community hanya mencapai 50\% dari sasaran di dalam pedoman Masterplan P2KH. Pencapaian belum maksimal tidak hanya pada peran pemerintah namun juga pada partisipasi masyarakat yang belum optimal dalam upaya perwujudan Kota Hijau. Kurang maksimalnya peran pemerintah dilihat dari upaya pemeliharaan taman dan juga kegiatan sosialiasi/penyuluhan yang belum optimal, sedangkan pada partisipasi masyarakat yaitu kurangnya kesadaran masyarakat terhadap pentingnya RTH bagi lingkungan perkotaan serta masih minimnya perilaku beberapa masyarakat dalam menjaga lingkungan sehingga mengakibatkan lingkungan terutama taman tidak terjaga dengan baik.

\section{3) Faktor-faktor yang Mempengaruhi Penerapan Green Open Space dan Green Community}

a. Lokasi taman yang kurang strategis karena tidak berada di jalan utama dan di pusat perkotaan.

b. Akses menuju taman tidak dilalui oleh sarana transportasi umum karena tidak berada di jalan kolektor dan aksesnya sulit dijangkau karena berada di jalan lingkungan yang jarang dilalui masyarakat.

c. Keberadaan vegetasi kurang optimal dalam memberikan keteduhan karena persebarannya tidak merata dan kondisi tanamannya yang masih berusia muda sehingga percabangannya tidak cukup lebar dalam menaungi taman.

d. Kondisi fasilitas yang tidak terawat dan tidak layak digunakan karena tidak adanya peninjauan terhadap kondisi fasilitas dan kurangnya kesadaran pengunjung dalam menjaga kebersihan fasilitas.

e. Pemanfaatan area belum dapat menunjang unsur bermain dan berolahraga karena tidak dilengkapi dengan taman bermain anak dan fasilitas olahraga.

f. Tidak memiliki daya tarik karena kurangnya fasilitas dalam mendukung berbagai kegiatan aktif yang dapat menarik perhatian pengunjung serta penataan taman yang kurang diperhatikan dalam memberikan fungsi estetika. 
g. Upaya pemeliharaan taman yang belum optimal dipengaruhi oleh kegiatan pemeliharaan yang hanya sebatas pemeliharaan akan vegetasi dan belum melakukan peninjauan serta pemeliharaan fasilitas secara rutin.

h. Aksi nyata dalam upaya perwujudan $\mathrm{P} 2 \mathrm{KH}$ belum berjalan secara berkelanjutan karena terkendala oleh dana serta kesibukan oleh masing-masing personil komunitas.

i. Kondisi fasilitas taman yang kotor dan aksi vandalisme pada beberapa fasilitas karena kurangnya pengawasan oleh pemerintah dan kesadaran masyarakat dalam menjaga dan memelihara kebersihan lingkungan.

\section{KESIMPULAN DAN SARAN}

\section{A. Kesimpulan:}

a. Hasil evaluasi penerapan Green Open Space terhadap kualitas taman pada Taman Stadion Utama dan Langenharjo kurang optimal dan masih jauh dari target sasaran, hal ini disebabkan oleh tidak memadainya fasilitas penunjang sehingga keberadaan taman belum dapat memenuhi fungsi sosial, selain itu karena lokasinya yang kurang strategis dan tidak memiliki daya tarik sehingga tidak dapat menarik minat pengunjung untuk datang.

b. Hasil evaluasi penerapan Green Open Space terhadap kualitas taman pada Taman Gajah Mada telah cukup maksimal didukung dengan persebaran vegetasinya yang merata dan memadainya jumlah serta jenis fasilitas pendukung, selain itu terdapat beberapa daya tarik yang cukup menarik perhatian pengunjung untuk dijadikan sebagai spot foto.

c. Hasil evaluasi penerapan Green Community belum maksimal karena upaya pemerintah dalam memberikan sosialisasi dan perawatan taman tidak berjalan secara berkelanjutan, selain itu kurangnya kesadaran masyarakat dalam menjaga dan merawat lingkungan.

d. Faktor-faktor yang mempengaruhi penerapan Green Open Space dan Green Community terhadap kualitas taman dilihat dari lokasi, akses, kondisi fasilitas, pemanfaatan area dan peran aktif dari masyarakat yang belum optimal.

\section{b. Saran}

a. Pemenuhan kuantitas taman yang masih kurang dengan menambah area RTH pada lahan-lahan kosong di area permukiman. 
b. Penataan Taman Stadion Utama dan Taman Langenharjo agar dapat difungsikan secara aktif oleh masyarakat

- Mengganti dan memperbaiki fasilitas yang rusak.

- Menambah fasilitas dalam mendukung kegiatan aktif masyarakat dengan menambah fasilitas bermain dan olahraga.

- Penataan pola tanaman disesuaikan dalam memberikan fungsi peneduhan dan estetika.

c. Perbaikan kolam retensi pada Taman Langenharjo dan Taman Gajah Mada agar menjadi daya tarik dengan menciptakan kondisi kolam yang bersih dan aman bagi pengunjung.

d. Memberikan sosialisasi terkait dengan P2KH secara lebih luas pada generasi muda terutama pada siswa sekolah dengan melakukan kerja bakti secara rutin di lingkungan perkotaan.

e. Mengadakan event tertentu dalam rangka mempromosikan keberadaan taman-taman agar lebih dikenal oleh masyarakat dan menjadikan taman yang aktif untuk berbagai kegiatan.

f. Meninjau kondisi dan jenis tanaman agar lebih aman bagi pengunjung dan tidak menimbulkan bahaya seperti dahannya yang mudah patah dan tanaman yang menimbulkan alergi serta racun.

g. Masyarakat Ikut aktif dalam setiap kegiatan yang mendukung perwujudan Kota Hijau yang diselenggarakan baik dari Pemerintah maupun instansi lain.

h. Menjaga lingkungan taman dari kegiatan yang merusak lingkungan.

i. Kajian Kuantitas Ruang Terbuka Hijau di Kecamatan Kendal dalam perwujudan Program Pengembangan Kota Hijau (P2KH).

j. Zonasi Ruang Terbuka Hijau dalam Program Pengembangan Kota Hijau (P2KH) di Kecamatan Kendal.

k. Persepsi Masyarakat terhadap Daya Tarik dalam Meningkatkan Aktivitas Pengunjung di Taman Kota Kecamatan Kendal.

\section{DAFTAR PUSTAKA}

Carr, Stephen, dkk. (1992). Public Space. Australia: Press Syndicate of University of Cambridge. 
Dunn, William N. (2000). Pengantar Analisis Kebijakan Publik. Yogyakarta: Gajah Mada University Press.

Fandeli, C. (2004). Perhutanan Kota. Yogyakarta: Fakultas Kehutanan Universitas Gadjah Mada.

Hakim, R dan H. Utomo. (2008). Komponen Perancangan Arsitektur Lansekap: PrinsipUnsur dan Aplikasi Desain. Jakarta: Bumi Aksara.

Nazaruddin.(1994). Penghijauan Kota. Jakarta: Penebar Swadaya

Zoer'aini. (2003). Prinsip-prinsip ekologi, ekosistem, lingkungan dan pelestariannya. Bandung: Bumi Aksara.

EDY. (2013). Kendal ingin Wujudkan Kota Hijau dalam Seputar Kota Kendal edisi September 2013.

MJ. (2016). Warga minta Taman Kota Weleri dijaga Petugas dalam Metro Jateng edisi Maret 2016. 